\title{
Operating Costs of Full-endoscopic Lumbar Spine Surgery in Japan
}

\author{
Hiroaki MANABE, ${ }^{1}$ Fumitake TEZUKA, ${ }^{1}$ Kazuta YamASHITA, ${ }^{1}$ \\ Kosuke SugIURA, ${ }^{1}$ Yoshihiro ISHIHAMA, ${ }^{1}$ Yoichiro TAKATA, ${ }^{1}$ \\ Toshinori SAKAI, ${ }^{1}$ Toru MAEDA, ${ }^{1}$ and Koichi SAIRYO ${ }^{1}$ \\ ${ }^{1}$ Department of Orthopedics, Institute of Biomedical Sciences, \\ Tokushima University Graduate School, Tokushima, Tokushima, Japan
}

\begin{abstract}
For full-endoscopic lumbar discectomy, operating costs are also important because expensive equipment are necessary. We surveyed the operating costs of surgical equipment necessary for full-endoscopic surgery together with surgical procedure reimbursement fees. A total of 295 cases of full-endoscopic surgery via a transforaminal approach were retrospectively analyzed. We calculated the frequency of damage and the unit purchase price of devices such as endoscopes, and surgical instruments such as grasping forceps for nucleotomy, high-speed drill bar, and bipolar forceps, and examined the operating costs in Japanese yen against the procedure fee per case. Endoscope breakage occurred seven times, and a payment of $¥ 760,000$ was necessary for trade-in and purchase of a new endoscope. The total breakage number of grasping forceps was 58 , and the purchase price per unit was $¥ 116,000$. Therefore, a total of $¥ 12,020,000$ was required for the 295 cases, and the calculated operating cost that accompanies equipment breakage was $¥ 40,000$ per case. In addition, about $¥ 118,000$ was required for disposable bipolar forceps and highspeed drill bar to be used intraoperatively for each case. Thus, for one case it is calculated that total $¥ 158,000$ is utilized for equipment from the surgical reimbursement fee per case specified by the Japanese Ministry of Health being ¥303,900. Minimally invasive procedures provide great benefit to patients; however, the eventual contribution to hospital profits is small and may not be sufficient. To resolve this issue, the cost of surgical equipment should be lowered and/or the surgical reimbursement fee of the full-endoscopic surgery should be raised.
\end{abstract}

Key words: operating cost, full-endoscopic surgery, lumbar disc herniation

\section{Introduction}

Lumbar disc herniation (LDH) is the most common cause of low back pain, and one of several surgical methods may be chosen for treatment. Previously, open discectomy was the standard procedure, but more minimally invasive methods are now preferred. At present, microscopic discectomy is considered gold standards in the management of LDH for favorable outcomes with respect to long-term followup. In contrast, full-endoscopic discectomy (FELD) provides significant benefits to patients compared with conventional open surgery in terms of hospitalization, postoperative pain, wound complications, and a more rapid return to the workplace, and is

Received June 18, 2019; Accepted September 6, 2019

Copyright $\odot 2020$ by The Japan Neurosurgical Society This work is licensed under a Creative Commons AttributionNonCommercial-NoDerivatives International License. rapidly spreading worldwide. ${ }^{1,2)}$ Especially, the posterolateral transforaminal approach can be performed under local anesthesia, and it is considered to be minimally invasive as well as regarding the anesthesia method. ${ }^{3)}$

However, in Japan, despite the fact that FELD are totally different procedures with distinct approaches, the aspects of surgical procedure fees are applied identically and are not clearly distinguished. In addition, in some institutions, facility investment costs cannot be determined because FELD requires initial costs such as endoscopic cameras, high speed drills, and bipolar devices. Furthermore, endoscopes and surgical instruments are small and prone to breakage, and so it should also be considered that the cost of equipment maintenance is burdensome.

Previous reports have described clinical outcomes. ${ }^{4,5)}$ However, few studies on operating costs have examined endoscopes and related equipment. We therefore conducted a retrospective analysis of medical record 
data with the aim of assessing the operating costs of full-endoscopic surgery.

\section{Materials and Methods}

A total of 295 cases of full-endoscopic surgery via a transforaminal approach including discectomy, foraminoplasty, and ventral facetectomy performed by four surgeons between January 2014 and September 2018 were identified from our institutional clinical data repository. In all cases, FELD via transforaminal approach was performed under local anesthesia using the modified method reported by Yeung and Tsou. ${ }^{6}{ }^{6}$ An $8-\mathrm{mm}$ incision was made $6-10 \mathrm{~cm}$ from the midline and a cannula was placed inside or outside the disc. After that, the foramen and ventral facet was resected as necessary. Informed consent was waived because there was no patient intervention and the study ensured patient data confidentiality.

The survey targets were the Karl Storz Endoscope (Karl Storz, Tuttlingen, Germany) (Fig. 1A) and related surgical instruments such as grasping forceps (Karl Storz, Tuttlingen, Germany) (Fig. 1B) for nucleotomy, a single-use high-speed drill bar (Nakanishi Inc., Tochigi, Japan) (Fig. 1C) and bipolar forceps (Elliquence, Baldwin, NY, USA) (Fig. 1D). We calculated the frequency of damage about endoscope and grasping forceps and the unit purchase price of all devices during the investigation period, and examined the running cost in Japanese yen against the procedure fee per case.

\section{Results}

Among the four surgeons, one was the senior author of this study and a board certified instructor under the Japan Orthopedic Surgery Society. The others were spinal specialists but were not certified instructors. They were conducting the full-endoscopic surgery under the guidance of the board certified instructor. The surgical codes specified by the Japanese Ministry of Health are all the same (K - $143-2)$, and the surgical procedure reimbursement fee per case is $¥ 303,900$. The endoscope was damaged seven times, $¥ 756,000$ was required as the difference between trade-in and purchase costs of the new endoscope at once, and the total amount of money spent was $¥ 5,292,000$. The grasping forceps was damaged a total of 58 times, the purchase price per unit was $¥ 116,000$; the total cost was $¥ 6,728,000$. From the above, a total of $¥ 12,020,000$ about endoscope and grasping forceps was required for the 295 cases (Table 1); the total operating cost that accompanies equipment breakage per case was $¥ 40,745$. In addition, a single-use drill bar $(¥ 29,912)$ and bipolar forceps $(¥ 87,912)$ are required depending on the cases and surgeon. And, we need about $¥ 117,824$ in addition, because we use both in most cases; the total operating cost per case was approximately ¥158,569.

$$
\begin{aligned}
\text { Operating cost } & =\frac{(\text { Grasping forces } \times 58)}{\text { Cases }}+\text { Drill bar }+ \text { Biploar } \\
& =\frac{5,292,000+6,728,000}{295}+29,912+87,912 \\
& =¥ 158,569 \text { per case }
\end{aligned}
$$

\section{Discussion}

Lumbar disc herniation refractory to conservative treatment is sometimes effectively treated by surgery.
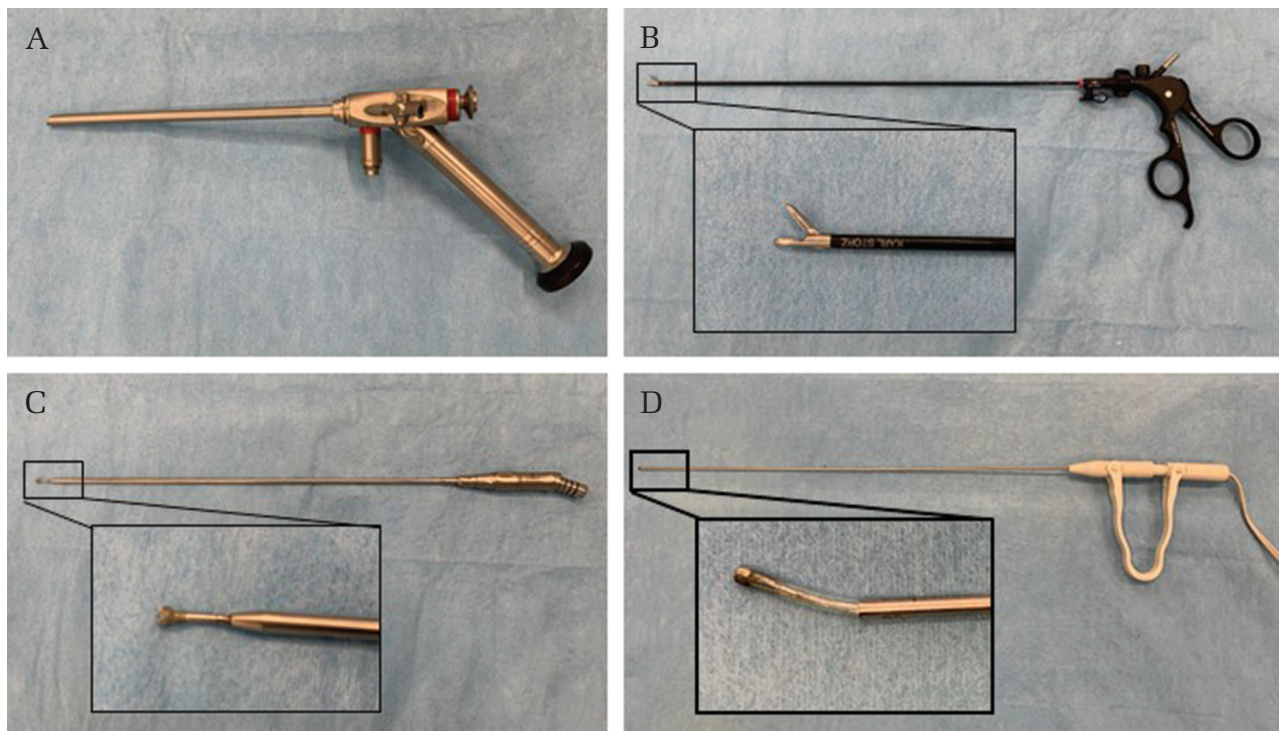

Fig. 1 Each slide shows devices examined: (A) endoscope, (B) grasping forceps, (C) drill bar, and (D) bipolar forceps. 
Table 1 Equipment cost required for 295 cases

\begin{tabular}{lccc}
\hline & Unit price & $\begin{array}{c}\text { Purchasing } \\
\text { quantities }\end{array}$ & Total \\
\hline $\begin{array}{l}\text { Endoscope } \\
\text { Grasping }\end{array}$ & $756,000^{*}$ & 7 & $5,292,000$ \\
forceps & 116,000 & 58 & $6,728,000$ \\
Total & & & $12,020,000$ \\
\hline
\end{tabular}

*Difference between purchase cost and trade-in price.

Since the first report of lumbar disc surgery in 1934 by Mixter and Barr ${ }^{7)}$ who performed a transdural discectomy, various less invasive techniques have been developed. In 1997, Foley and Smith ${ }^{8)}$ introduced the transmuscular approach for microendoscopic discectomy. Recently, FELD for LDH was introduced by Yeung and Tsou, ${ }^{6)}$ and is gaining popularity with expanding adaptation for canal and foraminal stenosis. ${ }^{3)}$ The concept of FELD is based on minimal tissue damage, while achieving a favorable clinical outcome comparable with conventional open surgery. ${ }^{4,5)}$ Patients are expected to have less back pain, shorter hospitalization, and a quicker return to daily activities compared with the conventional method. ${ }^{1,2)}$

In recent years, the annual number of spinal surgeries for $\mathrm{LDH}$ performed has increased, ${ }^{9)}$ with growing pressure to reduce costs while continuing to deliver high-quality care. Thus, research into more cost effective spinal surgery is becoming an increasingly important topic of discussion. ${ }^{10,11)}$ It has been reported that minimally invasive surgery is cost effective compared with conventional methods, ${ }^{12,13)}$ but doctors themselves also need to deepen their understanding of the associated costs, which are becoming increasingly relevant to surgeons. When surgeons are given information on procedural and equipment costs, cost savings are realized in response to that feedback. ${ }^{14,15)}$

The growing interest in the cost of expendable surgical items, number of instruments used, efforts toward efficient use of purchased equipment, and improving technology and endoscopic surgical procedure experience, should further reduce costs. However, the length of hospitalization is short due to the minimally invasive nature of FELD, and will yield no obvious benefits to the hospital. Specifically, when transforaminal approach is performed under local anesthesia, no anesthetic management fee can be obtained. As can be seen from our study, considering that the surgical reimbursement fee of the FELD method is $¥ 303,900$, the hospital’s profits are small while $¥ 158,000$ per case is necessary. We also should know about initial acquisition costs. Even excluding video equipment such as light source devices and monitors that are also compatible with arthroscope, we need initial costs of $¥ 4,500,000$ for a basic endoscope system such as external cylinder and assistive device, ¥3,500,000 for bipolar forceps main body system and ¥3,035,000 for high-speed drill main body system. Therefore, from the viewpoint of hospital management, it is difficult to provide FELD appropriately despite the high cost-effectiveness and marked benefits for patient-centered clinical outcomes.

There are two options for solving these problems. First is to increase surgical reimbursement fees. Depending on the complexity of the procedure and the benefit to the patient, higher fees should be set. Nevertheless, even with somewhat increased surgical fees, the cost effectiveness due to the widespread availability of minimally invasive surgery will have a greater impact on national healthcare cost savings. Second is to lower prices for endoscopes and related surgical instruments. Each of these items is expensive and it is difficult to reduce hospital expenditure unless the price itself is lowered, including disposable equipment.

There are several limitations to our research. First, the costs considered in this analysis were limited to the endoscope body and related equipment, and did not consider the depreciation and servicing contract. Second, our facility is an educational training facility and this could account for the frequency of damage being greater than expected. Therefore, if trainee doctors are excluded, the rate of damage may be lower. Finally, it is unclear exactly when the equipment was damaged. In some cases damage occurred during preparation and cleaning/ sterilization; therefore, the surgeon as well as all personnel who handle the equipment need to do so with caution.

\section{Conclusion}

Because FELD is a minimally invasive surgical procedure that can be performed under local anesthesia, it has made it possible to treat patients with poor general condition and/or who are unfit for open surgery due to underlying disease, and so it contributes to improvement of outcomes. To ensure that more patients receive this benefit, the surgical fee for FELD and the purchase cost of equipment should be made more affordable.

\section{Conflicts of Interest Disclosure}

All authors report no conflicts of interest concerning this article. 


\section{References}

1) Choi KC, Shim HK, Hwang JS, et al.: Comparison of surgical invasiveness between microdiscectomy and 3 different endoscopic discectomy techniques for lumbar disc herniation. World Neurosurg 116: e750-e758, 2018

2) Qin R, Liu B, Hao J, et al.: Percutaneous endoscopic lumbar discectomy versus posterior open lumbar microdiscectomy for the treatment of symptomatic lumbar disc herniation: a systemic review and meta-analysis. World Neurosurg 120: 352-362, 2018

3) Sairyo K, Chikawa T, Nagamachi A: State-of-the-art transforaminal percutaneous endoscopic lumbar surgery under local anesthesia: discectomy, foraminoplasty, and ventral facetectomy. J Orthop Sci 23: 229-236, 2018

4) Choi KC, Kim JS, Park CK: Percutaneous endoscopic lumbar discectomy as an alternative to open lumbar microdiscectomy for large lumbar disc herniation. Pain Physician 19: E291-E300, 2016

5) Ahn SS, Kim SH, Kim DW, Lee BH: Comparison of outcomes of percutaneous endoscopic lumbar discectomy and open lumbar microdiscectomy for young adults: a retrospective matched cohort study. World Neurosurg 86: 250-258, 2016

6) Yeung AT, Tsou PM: Posterolateral endoscopic excision for lumbar disc herniation: surgical technique, outcome, and complications in 307 consecutive cases. Spine (Phila Pa 1976) 27: 722-731, 2002

7) Mixter WJ, Barr JS: Rupture of the intervertebral disc with involvement of the spinal canal. $N$ Engl J Med 211: 210-215, 1934

8) Perez-Cruet MJ, Foley KT, Isaacs RE, et al.: Microendoscopic lumbar discectomy: technical note. Neurosurgery 51: S129-S136, 2002
9) Deyo RA, Mirza SK: Trends and variations in the use of spine surgery. Clin Orthop Relat Res 443: 139-146, 2006

10) Alvin MD, Miller JA, Lubelski D, et al.: Variations in cost calculations in spine surgery cost-effectiveness research. Neurosurg Focus 36: E1, 2014

11) Vertuani S, Nilsson J, Borgman B, et al.: A costeffectiveness analysis of minimally invasive versus open surgery techniques for lumbar spinal fusion in Italy and the United Kingdom. Value Health 18: 810-816, 2015

12) Fan CJ, Chien HL, Weiss MJ, et al.: Minimally invasive versus open surgery in the Medicare population: a comparison of post-operative and economic outcomes. Surg Endosc 32: 3874-3880, 2018

13) Kim CH, Chung CK, Kim MJ, et al.: Increased volume of lumbar surgeries for herniated intervertebral disc disease and cost-effectiveness analysis: a nationwide cohort study. Spine (Phila Pa 1976) 43: 585-593, 2018

14) Govaert JA, van Bommel AC, van Dijk WA, van Leersum NJ, Tollenaar RA, Wouters MW: Reducing healthcare costs facilitated by surgical auditing: a systematic review. World J Surg 39: 1672-1680, 2015

15) Kashlan ON, Wilson TJ, Chaudhary N, et al.: Reducing costs while maintaining quality in endovascular neurosurgical procedures. J Neurosurg 121: 1071-1076, 2014

Address reprint requests to: Hiroaki Manabe, MD, Department of Orthopedics, Institute of Biomedical Sciences, Tokushima University Graduate School, 3-18-15 Kuramoto-cho, Tokushima, Tokushima 770-8503, Japan.

e-mail: s52726362@yahoo.co.jp 